$\begin{gathered}\text { Revista do Departamento de Geografia } \\ \text { Universidade de São Paulo } \\ \text { www.revistas.usp.br/rdg } \\ \text { Volume Especial (2016) }\end{gathered}$
ISSN 2236-2878

\title{
TÉCNICA DE PESQUISA EM CLIMA URBANO COM FOCO NO SUBSISTEMA FÍSICO-QUÍMICO
}

\author{
TECHNICAL RESEARCH ON URBAN CLIMATE WITH A FOCUS ON \\ PHYSICOCHEMICAL SUBSYSTEM
}

\author{
Charlei Aparecido da Silva \\ Universidade Federal da Grande Dourados \\ charleisilva@ufgd.edu.br
}

\begin{abstract}
Resumo: O objetivo do estudo é apresentar técnica de pesquisa em clima urbano com foco no subsistema físicoquímico. Visa discutir um roteiro teórico-metodológico que valorize e incorpore a dinâmica climática da área de estudo, as condições dos tipos de tempo, as características do sítio urbano, o padrão construtivo, o processo de produção do espaço urbano e o uso do Handheld Laser Particle Counter modelo P311 da marca Airy Tecnology. De custo acessível o Handheld Laser Particle Counter modelo P311 apresenta-se como um equipamento de grande eficiência e passível de ser incorporado em estudos de clima urbano cujo escopo seja o subsistema físico-químico. Capaz de medir concentrações de partículas sólidas inaláveis em microgramas $(0,5 ; 2,5$ e 5,0 micrômetros) o equipamento permite identificar níveis de poluição prejudiciais à saúde humana. $\mathrm{O}$ roteiro proposto é viável para estudos de clima urbano que tenham como objetivo identificar e mensurar a qualidade do ar de áreas das cidades, espacializar a poluição e/ou subsidiar a elaboração medidas mitigadores e de políticas públicas.
\end{abstract}

Palavras-chave: Clima urbano; Subsistema físicoquímico; Qualidade do ar; Técnica de pesquisa.

\begin{abstract}
The objective is to present technical research in urban climate with a focus on physic-chemical subsystem. Aims to discuss a theoretical-methodological route that values and incorporates the dynamic climate of the study area, the types of weather conditions, the characteristics of the urban site, the constructive default, the process of production of urban space and the use of Handheld Laser Particle Counter model P311 brand Airy Tecnology. Affordable Handheld Laser Particle Counter Model P311 presents itself as a high-efficiency equipment and capable of being incorporated into urban climate studies whose scope is the physicochemical channel. Measuring concentrations of inhalable particulate matter in micrograms (0.5, 2.5 and 5.0 microns) allows the device to identify pollution levels harmful to human health. The proposed route is feasible for urban climate studies that aim to identify and measure the air quality of areas of cities, spatialize pollution and / or mitigating measures support the development and public policy.
\end{abstract}

Keywords: Urban climate; Physical-chemical subsystem; Air quality; Technical research. 


\section{INTRODUÇÃO}

As cidades constituem-se como o maior símbolo da construção social, da capacidade humana de transformar o espaço em função de suas necessidades, em alterar a natureza decorrente de suas ações. De fato, a cidade, materializada no urbano, é a expressão maior da invenção humana, de sua genialidade e, contraditoriamente, cada vez mais o lugar de conflitos sociais e ambientais. Dados da ONU apontam que mais de 50\% da população mundial hoje vive em áreas urbanas e, em 2050, esse percentual será de $70 \%$. Na América Latina relatório ONU-Habitat, o programa da ONU para Assentamentos Humanos, aponta que em 2020, 89\% da população viverá em cidades. E mais, será nos países em desenvolvimento que o crescimento das cidades dar-se-á de forma mais marcante nas próximas décadas - condição na qual o Brasil se encontra.

No Brasil o censo de 2010 do IBGE aponta que 84,36\% da população brasileira vive e trabalha em áreas urbanas. Assim as cidades serão cada vez mais o lugar onde os impactos ambientais se farão presentes e terão maior significância, sejam pelas desigualdades sociais, ou, pela incapacidade de lidarmos com os conflitos advindos da relação homem-natureza.

No que tange ao clima, o estilo de vida urbano tem se demonstrado como um dos principais vetores de mudanças climáticas. Para Hogan (2009, p. 16) "a expansão urbana transforma e fragmenta a paisagem, comprometendo tanto a diversidade biológica quanto a capacidade de ecossistemas de amortizar as consequências da atividade humana". Desse modo as transformações causadas no arranjo e na organização do geossistema, o qual se apresenta imediatamente como substrato para a existência e o crescimento das cidades, fazem surgir novos processos de inter-relação e interdependência que deveremos entender e lidar. A vulnerabilidade climática em áreas urbanas será assim pauta de grande importância nas próximas décadas e nortearão as políticas públicas que visam orientar o crescimento das cidades.

No Brasil os estudos de clima urbano têm se concentrado em grandes áreas metropolitanas, quase sempre localizadas nas regiões costeiras, onde estão as maiores concentrações populacionais e também o maior número de cidades. Contraditoriamente pouco se sabe dos climas urbanos de cidades pequenas e médias, poucos estudos foram realizados no Brasil continental, área na qual se verifica intenso crescimento urbano.

Sob o ponto de vista climático os estudos de clima urbano têm avançado principalmente na incorporação de novas tecnologias e técnicas. O incremento das tecnologias de informação, o desenvolvimento de softwares e hardwares, a criação de novos equipamentos, a massificação e a disponibilização de imagens de satélites tem contribuído significativamente para a realização de estudos cujo teor principal se volta para o entendimento da influência do urbano no clima local e, também, global. O desafio consiste em compreender a articulação do clima local produzido pelas cidades e suas reais conexões com a dinâmica climática global - sobre isso, em especial, os estudos de clima urbano muito têm que avançar.

A cidade é assim sob o ponto de vista climático o local mais desafiador para compreensão da relação homem-natureza haja vista as dinâmicas socioeconômicas postas sobre a natureza. Nas palavras de Monteiro (2004, p. 16) isso significa que:

(...) a cidade é aquela que melhor se presta a comprovação dessa integração. Como concentração humana edificadora em um dano lugar, ela é a sede de alto grau de derivações ambientais. Não se trata de apenas de avaliar a implantação de uma massa edificada, mas também de uma série de alterações promovidas sobre o condicionamento geológico do sítio.... E, mais ainda, a cidade como aglomeração humana concentra e expõe o resultado desse trabalho exploratório da natureza, gerador de uma economia que, aliada a política, expõe o caráter da sociedade. Em síntese os benefícios e malefícios na natureza e na edificação geram o produto ambiental, intimamente associado àquele socioeconômico.

O clima das cidades, o clima urbano, dessa forma não deve ser estudado ou analisado isoladamente ou a partir apenas de parâmetros ou modelos matemáticos, pois se incorre no erro de simplificá-lo em demasia - Monteiro (1990; 1999). A concepção geográfica do clima deve incorporar a noção da capacidade 
do urbano em gerar climas específicos que se materializam na forma de tipos de tempo, esses vivenciados pelos moradores das cidades no cotidiano. Essa noção de concepção geográfica do clima norteia a escola de estudos do clima proposta por Monteiro no ano 1976 e se materializa na proposição do S.C.U. (Sistema Clima Urbano), o qual tem sido o grande referencial teórico-metodológico para os estudos de clima urbano no Brasil. As proposições de Monteiro (1976) ressaltam a importância do estudo do clima urbano a partir dos subsistemas termodinâmico, físico-químico e hidrometeórico, respectivamente os canais de percepção conforto térmico, qualidade do ar e impacto meteórico.

É oportuno registrar que dadas às dimensões continentais do Brasil, sua diversidade climática, as dinâmicas sócio-espaciais e econômicas postas nesse século XXI, há urgência de compreendermos o quanto o clima está ou não sendo alterado localmente e o real significado dessas mudanças, bem como suas dimensões. Estudos têm demonstrado o crescimento e aumento das cidades em todo o território brasileiro, o surgimento de novas dinâmicas, arranjos e padrões produtivos, mas, nesse momento, mesmo reconhecendo avanços das últimas décadas e o aumento das pesquisas, os estudos de clima urbano não têm crescido na mesmo proporção - não estamos respondendo no mesmo ritmo, na mesma intensidade. No que tange aos estudos sobre a poluição atmosférica, com foco no subsistema físico-químico o quadro agrava-se ainda mais, depara-se com uma realidade marcada com pouquíssimos trabalhos e pesquisas desatualizadas e/ou que priorizam quase sempre as áreas metropolitanas, como se não ocorresse poluição atmosférica nas cidades pequenas e médias. Mudar essa realidade é um grande desafio, mas, ao mesmo tempo instigante. É sob esses pressupostos que o presente trabalho é construído, objetiva-se debater pesquisas de clima urbano cujo escopo seja o subsistema físico-químico, tomando como parâmetro o estudo realizado na cidade de Dourados, Mato Grosso do Sul, Brasil, utilizando-se o equipamento Handheld Laser Particle Counter MODEL P311 da marca Airy Technology.

\section{O subsistema físico-químico no Brasil: o canal de percepção qualidade do ar}

No que tange aos subsistemas e canais de percepção propostos por Monteiro (1976) para o estudo do clima urbano o subsistema físico-químico foi aquele que menos avançou, poucos foram os trabalhos realizados por geógrafos cuja temática central tenha como escopo a compreensão da dinâmica e as características do canal qualidade do ar em contraposição a produção do espaço urbano.

Na Geografia a tese de doutorado de Lucy Pinto Gallego, defendida no ano de 1972, orientada por Carlos Augusto de Figueiredo Monteiro, portanto quatro anos antes da publicação de sua obra clássica Teoria Clima Urbano, é um registro pioneiro do estudo de tipos de tempo, poluição atmosférica e identificação da qualidade do ar sob o ponto de vista geográfico. Tendo como objeto de analise a cidade do Rio de Janeiro, a tese versa sobre a importância da mensuração das partículas em suspensão e o entendimento dos tipos de tempo, com a finalidade de determinar a poluição atmosférica da cidade, identificar a qualidade do ar e correlacioná-la com a dinâmica da cidade. Nela estão postulados daquilo que viria a ser parte da Teoria Clima Urbano paradigma hoje utilizado por quase a totalidade dos pesquisadores da Geografia que se aventuram em estudar clima urbano.

Ely (2006) aponta com propriedade que pouquíssimos trabalhos enfocando o subsistema físicoquímico foram efetivamente realizados no período de 1944-2003 na Geografia, apenas nove trabalhos são citados, ou seja, pouco se conhece sobre a qualidade do ar das cidades brasileiras. Sobre esse mesmo aspecto Zavattini (2004) ao inventariar os estudos de clima no Brasil, no período de 1971-2000, isso a partir das teses e dissertações defendidas nos Programas de Pós-Graduação em Geografia, identifica quatro trabalhos, os quais estão presentes em Ely (op. cit.).

De fato, esse descompasso, essa desproporção, foi registrado por Mendonça (2003) ao estudar a evolução e as tendências dos estudos de clima urbano no Brasil. Para esse autor evidencia-se maior número de trabalhos no subsistema termodinâmico, seguido pelo hidrometeórico. Até o ano de 2000 Mendonça (2003) identificou, a partir de dados dos Anais do Simpósio Brasileiro de Climatologia Geográfica, apenas vinte trabalhos com foco no subsistema físico-químico, sendo que para as regiões Centro-Oeste e Norte não há registro de qualquer trabalho, de qualquer pesquisa realizada sobre poluição atmosférica de cidades dessas 
regiões sob a ótica da Geografia. Agrava o quadro o fato de cinquenta por cento dos trabalhos serem provenientes de pesquisas realizadas em duas cidades, São Paulo e Rio de Janeiro (Tabela 1).

Tabela 1: Pesquisas realizadas com foco no subsistema físico-químico até o ano de 2000 na Geografia. Adaptado de MENDONÇA (2003, p.184-185).

\begin{tabular}{ccc}
\hline \multirow{2}{*}{ Região } & Cidade & $\begin{array}{c}\text { Número de trabalhos no subsistema } \\
\text { Físico-Químico no Brasil até o ano de 2000 }\end{array}$ \\
\hline \multirow{2}{*}{ Sul } & Santa Cruz do Sul/RS & 01 \\
& Curitiba/PR & 01 \\
& Londrina/PR & 03 \\
\hline \multirow{3}{*}{ Sudeste } & São Paulo/SP & 07 \\
& Limeira/SP & 01 \\
& Rio de Janeiro/RJ & 03 \\
& Volta Redonda/RJ & 01 \\
& Uberlândia/MG & 01 \\
Nordeste & Juiz de Fora/MG & 01 \\
\hline
\end{tabular}

Fica evidente assim que as informações presentes em Mendonça (2003), Ely (2006) e Zavattini (2009) convergem e corroboram para os argumentos de que faltam estudos direcionados ao subsistema físico-químico. Ou seja, na Climatologia os geógrafos ainda têm dado pouquíssima atenção ao subsistema físico-químico cujas pesquisas aparentemente estão sendo desenvolvidas prioritariamente por outras áreas do conhecimento, em especial na Física Atmosférica, Química e Meteorologia, são nessas áreas que hoje se encontra grande parte das referências bibliográficas, dos estudos, os quais não tratam da espacialidade têmporo-espacial fenômeno e sua relação com a sociedade. Durante a construção desse texto identificou-se duas dissertações apenas sobre o tema nos últimos dez anos: Heiber (2006); Santos (2014). Ousa-se assim dizer que na Geografia ainda não se tem a mesma eficiência, a práxis de pesquisa, que se constata nos trabalhos que abordam os subsistemas termodinâmico e hidrometeórico. Trabalhos como de Cançado (2006); Aleixo e Sant'Anna Neto (2014) que demonstram e discutem a intima relação entre clima-poluição-saúde na verdade são exceções.

Mas quais são os motivos, os empecilhos para a realização de pesquisas no âmbito do subsistema físico-químico na Geografia brasileira? Por quais motivos as proposições feitas por Monteiro (1976), para o subsistema físico-químico, não tiveram a mesma atenção e desenvolvimento que os outros subsistemas e canais de percepção do Sistema Clima Urbano (SCU)? Uma das explicações está em Mendonça (2003, p.180), em países desenvolvidos os estudos sobre a qualidade do ar quase sempre ocorrem em concomitância ao termodinâmico, mas, em países em desenvolvimento, como o caso do Brasil, a industrialização tardia e/ou a forma da concentração industrial, acabou por ser um desmotivador haja vista que o conceito de poluição atmosférica sempre esteve intimamente ligado a grandes metrópoles e zonas industriais. Dessa forma pouco se pesquisou sobre a qualidade do ar de cidades pequenas e médias, as quais são maioria no Brasil. Acrescenta-se o custo elevado dos equipamentos e a dificuldade de adquiri-los, a aquisição sempre se apresentou como um problema para criação de redes e/ou pontos de monitoramento que viessem a subsidiar os estudos da qualidade do ar das cidades brasileiras. Fica evidente que a aquisição de dados, principalmente, nas escalas horárias e diárias, configurou-se como o grande limitador ao longo dos últimos 30 anos, desde a proposição do SCU.

Todavia para que haja uma mudança do contexto apresentado torna-se necessário rever primeiramente a forma de encarar-se aquilo que comumente é tido como a gênese da poluição atmosférica das cidades, ir além da contaminação provocada pelas indústrias e incorporar outras dinâmicas materializadas na produção do espaço urbano. Fora dos grandes centros industriais, das metrópoles, nas cidades pequenas e médias, vivenciam-se dinâmicas que envolvem a ocorrência de queimadas, frota de veículos desregulados, padrão construtivo inadequado e ruas sem cobertura asfáltica que contribuem muito 
mais significativamente para poluição atmosférica. São essas variáveis que atuam como agentes poluidores do ar muito mais que os contaminantes proveniente das indústrias. Além disso, a legislação ambiental brasileira forçou a instalação de filtros e/ou mudança nos processos de produção que tem minimizado e muito a emissão de poluentes na atmosfera. Um debate acerca dos parâmetros mais significativos para a Geografia sobre a poluição atmosférica das cidades está por ser construído, isso é fundamental e necessário para que possamos ter um arcabouço que permita o desenvolvimento das pesquisas com maior precisão, objetividade e eficiência no âmbito do subsistema físico-químico.

Não obstante o momento atual apresenta-se como promissor para o desenvolvimento de pesquisas no subsistema físico-químico, no canal de percepção qualidade do ar. Na última década surgiram novos equipamentos, mais precisos, mais fácies de serem instalados e operados, capazes de mensurar e registrar diversos parâmetros, sejam gases ou partículas em suspensão na atmosfera. Com menores custos e possíveis de serem adquiridos sem grande dificuldade. Mesmo aqueles importados, no passado de difícil acesso, hoje são encontrados com certa facilidade na rede mundial de computadores. As empresas passaram a ter representantes no Brasil atuando nas áreas de venda e suporte técnico, além do que o processo de importação se tornou mais fácil. Essas realidades de aquisição de equipamentos criam novas perspectivas e duas condições importantes surgem: autonomia e mobilidade. Autonomia para instalação de pontos de monitoramento e redes, condição que já ocorre nos estudos dos subsistemas termodinâmico e hidrometeórico, levando a uma independência frente a órgãos governamentais e instituições privadas. Há uma maior mobilidade para mensurar os dados nas escalas verticais e horizontais haja vista que muito dos equipamentos são versáteis e portáteis.

O desafio dessa forma não reside mais exclusivamente na existência e na possibilidade de aquisição de aparato técnico e equipamentos. Na existência de redes de monitoramento que possam fornecer dados primários. O grande desafio está na capacidade de identificarmos quais são os aparelhos recomendados, suas finalidades, limitações e raio de abrangência. Quais são os parâmetros mais importantes no estudo do canal de percepção qualidade do ar e como correlacioná-los com a produção do espaço. Sobre essas questões muito ainda temos que descobrir na Geografia, na Climatologia.

\section{A proposição de procedimentos de pesquisa}

Em Monteiro (1990) há um apanhado de sua experiência frente ao estudo do clima urbano, são apresentadas estratégias para instrumentalizar as operações de campo na análise geográfica do clima. Mesmo não dando ênfase especificamente ao subsistema físico-químico os postulados presentes são essências para proposição do roteiro de pesquisa ora proposto são elas: as relações internas entre os atributos geoecológicos do sítio, morfologia e as funções urbanas.

A proposição envolve compreender a horizontalidade espacial do urbano, suas características, bem como as dinâmicas cotidianas, para, com isso, associá-las as condições atmosféricas vigentes, ao tipo de tempo predominante no momento da mensuração dos parâmetros que servirão de base para determinar a qualidade do ar da área analisada. A qualidade do ar assim será imediatamente resultado da interação dos forçantes com os elementos do clima, no urbano decorrente das ações antrópicas, em contraposição as condições atmosféricas que favoreçam ou não a dispersão dos contaminantes que ocasionam a poluição do ar.

Compreendido isso se conclui que a escala horizontal mais apropriada para os estudos do subsistema físico-químico é de dezenas de metros, cujas variações ocorrem entre 1:5.000 e, no máximo, 1:25.000. Nessa escala identificam-se os fragmentos e as características do urbano e, por consequência, são identificados com mais facilidade os agentes causadores das forçantes que alteram as características dos elementos da atmosfera e, portanto afetam qualidade do ar. No que tange a escala vertical poderá fazer-se diversos cortes a fim de identificar-se possíveis variações nas camadas da atmosfera, todavia, é recomendável, principalmente para estudos que visem a saúde pública, que os parâmetros a serem mensurados sejam amostrados a uma altura de no mínimo 1,5 m e não superior a $2 \mathrm{~m}$. Os estudos no canal qualidade do ar devem assim privilegiar a articulação das escalas vertical e horizontal, o entendimento das características da cidade, e, 
concomitantemente, ter clareza no que tange a escolha da técnica de amostragem e o parâmetro que será efetivamente analisado/mensurado (Figura 1).

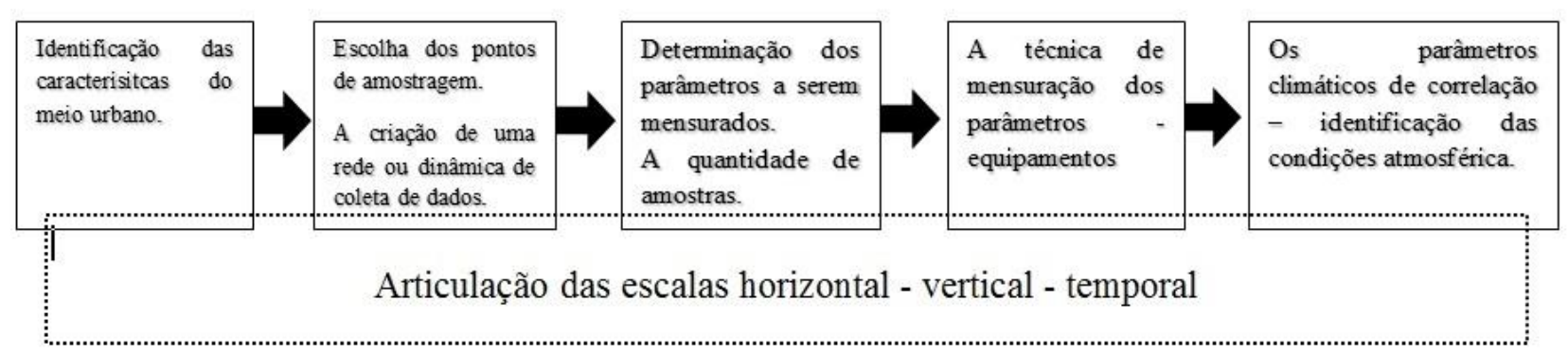

Figura 1: Prioridades de critérios no estudo do canal qualidade do ar. Organização: O autor (2016).

\section{A amostragem e a utilização do Handheld Laser Particle Counter modelo P311}

O Handheld Laser Particle Counter MODEL P311 da marca Airy Technology (Figura2) mensura a quantidade de partícula sólida em suspensão no ar em diâmetro $(0,5 \mu \mathrm{m} ; 2,5 \mu \mathrm{m}$ e $5,0 \mu \mathrm{m})$. Sua utilização adequa-se com eficiência aos estudos de qualidade do ar haja vista que sua precisão em micrômetros $(\mu \mathrm{m})$ atende as exigências internacionais, principalmente no que se refere aos estudos voltados a saúde pública. A contagem das partículas sólidas presentes na atmosfera se dá por laser e pode ser usado em ambiente externo, condição essencial para os estudos geográficos de clima urbano, não menos importante, o aparelho converge para aquilo descrito na ABNT (1997).

A capacidade de armazenamento é de até 8000 registros o que permite criar uma longa série de dados que podem ser trabalhados no software fornecido pelo fabricante. Armazenado em (*.txt) os dados amostrados também podem ser migrados com facilidade para outros softwares estatísticos. A desvantagem, sua limitação, reside na ausência de um datalogger, o acionamento depende de um usuário. No estudo de Santos (2014) optou-se pela construção de uma plataforma desmontável a fim de padronizar a altura, o processo de coleta dos dados.

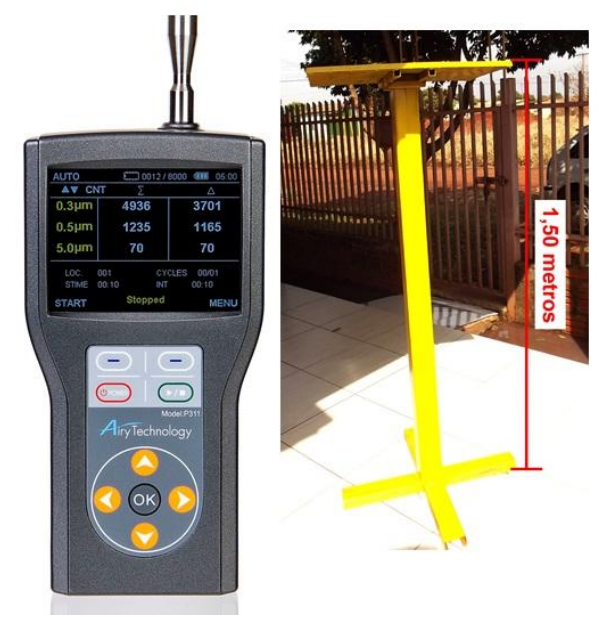

Figura 2: Equipamento para registrar a quantidade de material particulado na atmosfera. Fonte: Santos (2014) 
Seguindo a proposta da Figura 1, depois de realizado o estudo das características do urbano, usando como subsídio imagens de satélite, é indispensável identificar as áreas prioritárias de amostragem, sugere-se três critérios básicos: o adensamento urbano; a dinâmica da área (essencialmente fluxo de veículos, atividades realizadas e circulação de pessoas) e as características no entorno do ponto de amostragem. A fim de registrar objetivamente esses critérios propõe-se uma ficha de amostragem (Figura 3). Observa-se na ficha uma valorização e articulação entre a escala horizontal e as características do entorno do ponto de amostragem. Outra condição importante é o registro da coordenada geográfica condição que permite utilizar $\mathrm{s}$ informações em SIGs e espacializar os resultados com maior precisão e correlacioná-los com outros parâmetros. De posse dos dados amostrados propõe-se a construção de uma prancha (Figura 4) que facilite a analise conjuntamente das informações, valorizando a proposta de Monteiro (1976).

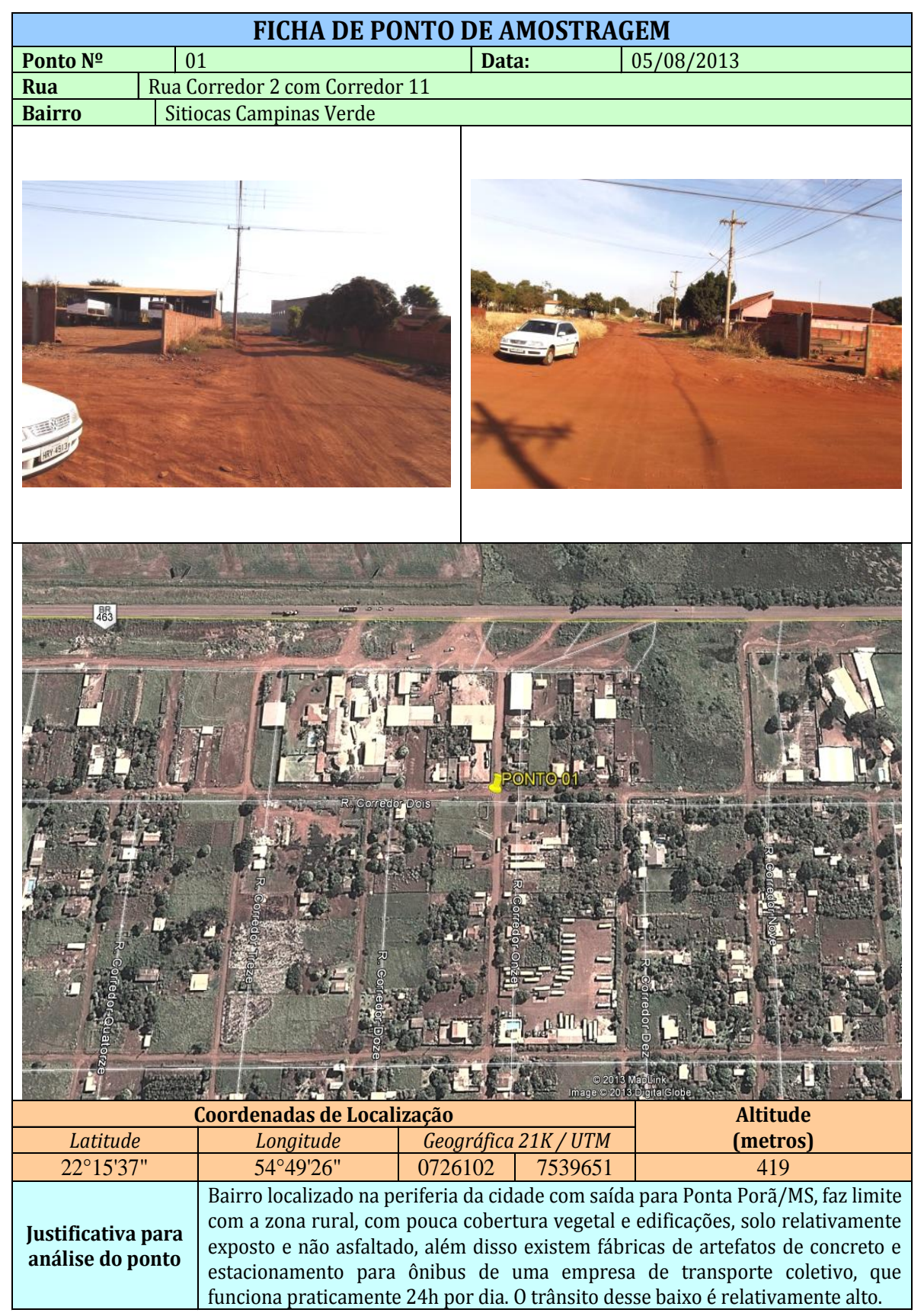

Figura 3: Ponto de amostragem, características do urbano e sua articulação com a escala horizontal. Fonte: Santos (2O14). 
A proposição da prancha envolve articular o padrão espacial urbano com a concentração de partículas sólidas registradas no período amostrado, isso em concomitância as condições atmosféricas locais e sinóticas. A qualidade do ar é assim resultado dessa interação e indicada de forma qualitativa a partir da concentração de partículas sólidas, tendo como base os parâmetros estabelecidos na Resolução do CONAMA n ${ }^{\circ}$ 03/90 (Figura 4). A prancha permite analisar e explicar a gênese da poluição indicando e sua relação direta com a produção do espaço urbano, bem como suas consequências para a sociedade.

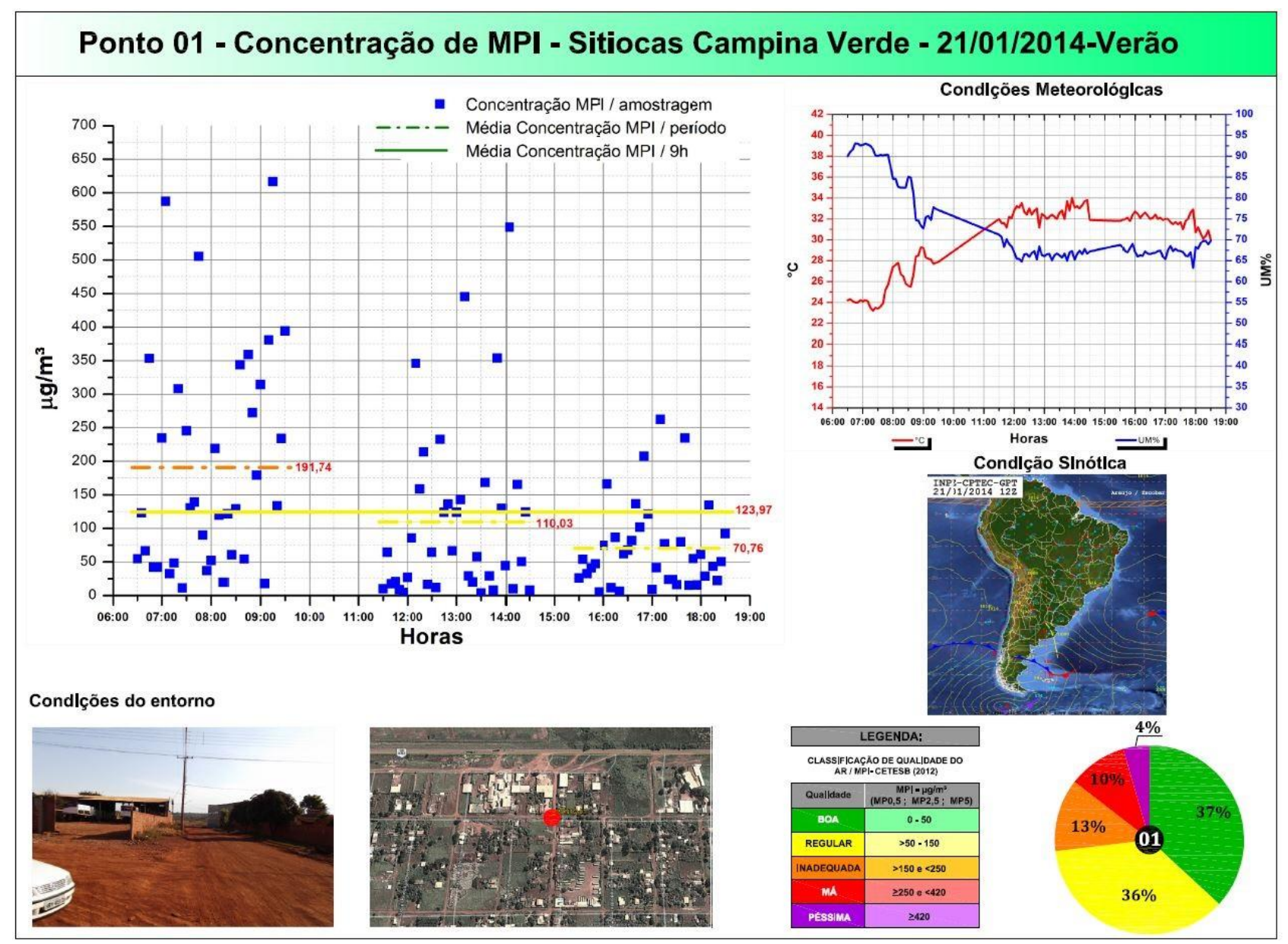

Figura 4: Articulação dos dados: padrão urbano, concentração de partículas sólidas e características do tempo. Organização: O autor (2014), a partir de dados presentes em Santos (2014).

\section{CONCLUSÃO}

$\mathrm{Na}$ Geografia fica evidente que pouquíssimos são os grupos de pesquisa brasileiros que estão propondo o uso de novas técnicas e equipamentos para a realização de pesquisas de clima urbano no subsistema físico-químico, assim parece oportuno debater o roteiro ora apresentado, o qual inclui o uso do Handheld Laser Particle Counter MODEL P311. Como não foi objetivo analisar e discutir resultados específicos vale a ressalva de como a proposta parece eficiente e exequível ao dar autonomia ao pesquisador, principalmente em cidades que não dispõe de redes oficiais ou deseja-se analisar diversos pontos do tecido urbano. Para aqueles que quiserem se aprofundar e conhecer melhor os resultados alcançados com o uso do equipamento recomendo a leitura do trabalho de Santos (2014). Além disso, torna-se claro a importância em articular as escalas horizontais e verticais, de apresentar as condições do tipo de tempo predominante, destacando a direção e velocidade do vento, a umidade relativa, a temperatura e as condições sinóticas. Em pesquisas realizadas no Laboratório de Geografia Física da UFGD (www.lgf.ggf.br), a proposta ora discutida permitiu registrar as variações das partículas sólidas em função das características do local e da dinâmica da cidade - vide as concentrações horárias registras e apresentadas na Figura 4. Os procedimentos propostos e 
os resultados obtidos nos ensaios convergem com a proposta de Monteiro para o Sistema Clima Urbano. Não obstante o parâmetro mensurado, partículas sólidas, é universal e permite quantificar e qualificar a qualidade do ar com propriedade - o parâmetro está presente em estudos com o mesmo teor no Brasil e no exterior. No Brasil especificamente o parâmetro se faz presente na legislação (Resolução do CONAMA no 03/90) e é utilizado como referência como órgãos e/ou instituições governamentais, como a CETESB (Companhia Ambiental do Estado de São Paulo). Que esse exercício posto na forma textual gere outras experiências profícuas e debates. Que possamos ampliar de fato os estudos no subsistema físico-químico e os estudos da qualidade do ar em cidades pequenas e médias em um futuro próximo. Passados 40 anos da proposição do SCU parece-me oportuno e pertinente enfrentarmos esse desafio.

\section{AGRADECIMENTOS}

Agradeço ao PPGG/UFGD pelo o apoio no desenvolvimento da pesquisa. A PROPP/UFGD pela compra do equipamento de amostragem por meio do programa Pró-Equipamentos/CAPES. Ao acadêmico Vladimir Aparecido dos Santos que aceitou o desafio de pesquisar a qualidade do ar de uma cidade do interior do Brasil, e, também, aos acadêmicos do LGF (Laboratório de Geografia Física) que me auxiliaram na revisão e na formatação da versão final desse texto. Não posso deixar de agradecer a ABClima, nesse momento representada pela diretoria da gestão 2014/2016, a qual não teceu esforços para que essa edição comemorativa da obra Teoria e Clima Urbano do Professor Carlos Augusto de Figueiredo Monteiro pudesse ser publicada. Aos editores da RDG agradeço pelo espaço concedido, parabéns pela forma que conduziram a publicação desse Volume Especial.

\section{REFERÊNCIAS}

ASSOCIAÇÃO BRASILEIRA DE NORMAS TÉCNICAS - ABNT, 1997 : Material particulado em suspensão no ar ambiente - determinação da concentração total pelo método do amostrador de grande volume. NBR 9547: 1986, 14 p.

ALEIXO, N. C. R. ; SANT'ANNA NETO, J.L. . Condicionantes climáticos e internações por pneumonia: estudo de caso em Ribeirão Preto/SP. Revista do Departamento de Geografia (USP), v. 27, p.1, 2014. CANÇADO, J. E. D. et al., 2006 : Repercussões clínicas da exposição à poluição atmosférica. J Brás Pneumol. 32(Supl 1), p. 5-11.

ELY, D. F. Teoria e método da Climatologia Geográfica brasileira: discursos e práticas. Tese (Doutorado em Geografia). Universidade Estadual Paulista, Presidente Prudente (SP), 2006.

GAllego, Lucy Pinto. Tipos de tempo e poluição atmosférica no Rio de Janeiro (um ensaio em climatologia urbana). Tese (Doutorado em Geografia). Universidade de São Paulo, São Paulo (SP), 1972.

HEIBER, R. F. D. Poluição do ar por veículos automotores e tipos de tempo em áreas metropolitanas: a elaboração de um roteiro metodológico. Dissertação (Mestrado em Geografia). Universidade Estadual Paulista, Rio Claro (SP), 2006.

HOGAN, D. J. População e mudanças ambientais globais. In: HOGAN, D. J. ; JUNIOR, E. M. (Orgs.). População e mudanças climáticas. Dimensões humanas das mudanças ambientais globais. Campinas: NEPO/Unicamp, 2009. p. 11-24.

MENDONÇA, F. O estudo do clima urbano no Brasil: evolução, tendências e alguns desafios. In: MONTEIRO, C. A. de Figueiredo e MENDONÇA F. Clima urbano. São Paulo: Contexto, 2003.

MONTEIRO, C. A. de F. A cidade desencantada - entre a fundamentação geográfica e a imaginação artística. In: MENDONÇA, F. (Org.). Impactos socioambientais urbanos. Curitiba, Editora da UFPR, 2004. p. 13-78.

O estudo geográfico do clima. Florianópolis: Ed. da UFSC/Imprensa Universitária, 1999.

Por um suporte teórico e prático para estimular estudos geográficos de clima urbano no Brasil. GEOSUL, Florianópolis, ano V, n. 9 , p.7-19, 1990. Disponível em < https://periodicos.ufsc.br/index.php/geosul/article/view/12737/11903> Acessado em outubro de 2016

Teoria e clima urbano. Tese (Livre Docência), Universidade de São Paulo, São Paulo, 1976. 
SANTOS, V. A. dos. A qualidade do ar de Dourados (MS): uma contribuição aos estudos de clima urbano com foco no canal físico-químico. Dissertação (Mestrado em Geografia), Universidade Federal da Grande Dourados, Dourados (MS), 2014.

ZAVATTINI, J. A. Estudos do clima no Brasil. Campinas - SP: Alínea, v. 1, 2004. 